\title{
Leadership Strategies and Decision Support Systems Based AI in the Developing Economies: Perspectives from Ghanaian Banking Sector
}

\author{
Moti Zwelling \\ Ariel Cyber Innovation Center, \\ Ariel University, Ariel, Israel \\ motiz@ariel.ac.il
}

Aaron R. Opoku-Ahene

International School for Social and Business Studies, Celje, Slovenia aahene@sinapiaba.com

\begin{abstract}
Purpose: Is to help leaders and managers of financial institutions, especially banks to acknowledge the importance of decision support systems based AI in helping them take effective decisions.
\end{abstract}

Study design/methodology/approach: The study employed qualitative research techniques to gather data for analysis. This technique was chosen because of the nature of the study which intends to derive "more depth" data from the encounters of participating respondents. Furthermore, a study was carried out by investigating others' interpretations and then filtering them to construct knowledge that was used to design a conceptual model to establish the bank leader's ability to adopt IT Systems based AI.

Findings: It was established that AI-based technology is needed for service improvement and managers are keen to adopt it for decision making in the banking sector in Ghana.

Originality/value: Although it is evident from literature that some work has been done on Artificial Intelligence (AI) in relation to banking industry in general. However, decision support systems based AI and how it affects decision of leadership in the banking industry in Ghana, especially in the current times of Covid-19 pandemic and banking clean-up exercise in Ghana is yet to be explored thoroughly.

Keywords: Artificial Intelligence, Decision Support Systems, Fintech, Covid-19, Leadership, Bank.

\section{Introduction}

Artificial Intelligence (termed as "AI”) and decision support systems have been developed dramatically in many areas of our lives. Such a development had not passed organizations, as well as the Finance sectors. The literature shows that to improve leadership and management approaches in the finance sector, technologies based AI may be utilized to improve these objectives.

According to Western (2019), leadership encompass the ability of an individual, group or organization to influence or guide other persons, teams, or the entire society. Contingency theories in leadership both in empirical and practice put forth the idea that a leader's success hinges on the specific environmental conditions that may exist and this must be coupled with general economic outlook Randall (1996) This was the motivation for artificial intelligence (AI) and its revolutionary implications on the global economy especially the recent one relating to the financial technology revolution, termed as "Fintech" (Finance Technology). Van (2018) defined Fintech as the technology and innovation that aims to compete with traditional financial methods in the delivery of financial services. The phenomenon led to McCarthy (1995 p.3) coined the term AI as "The science and engineering of making intelligent machines". This definition has over the five decades been refined to mean simulation of human intelligence in machines that are programmed to think like humans and mimic in their actions (Russell and Norvig, 2016). The interesting part of AI is the non-existence of a widely accepted definition 
(Kirsh, 1991; Allen, 1998; Hearst and Hirsh, 2000; Brachman, 2006; Nilsson, 2009; Bhatnagar et al., 2018; Monett and Lewis, 2018). All these studies confirmed this assertion and both researchers and practitioners agreed that it will be unrealistic to expect a commonly accepted definition.

Technology has been a lifeline to developing countries during the COVID-19 crisis, by helping to maintain essential services more particularly in the financial sector. Leaders in this sector were forced to take measures to offer a glimpse of a brighter future by asking employees to stay at home and work. Even before the Covid pandemic, commercial usage of AI was expanding rapidly in developing economies in fields ranging from manufacturing, energy, education and financial services. The lockdowns and travel restrictions imposed have exacerbated the leadership's challenges presented by the pandemic. This is where leadership from various executives in the developing economies are required to champion and embrace strategic Information technology such as AI in mitigating and rebuilding effort, helping to boost productivity and foster a new generation of innovative companies. To seize this opportunity, executives or managers in the developing economies had to prepare for this AIdriven future especially in the financial sector. Preko and Kester (2015) for example, indicated that financial institutions will have to reconsider how to embrace the opportunity to integrate applications and AI-based systems in the finance sector. As technology becomes more intelligent, leaders won't just be in charge of making everyday decisions. The next generation of leaders must reinforce the human aspect of decision-making, as AI takes over data-driven and contextual decisions.

Concerning Ghana's banking sector, the first AI laboratory was opened in 2019 in Accra by Google. The tech giant established the laboratory to support researchers with the tools and environment necessary to develop AI products and to solve numerous problems faced across the continent. The laboratory was aimed to create awareness among executives in the banking sector in Africa. This was the start of AI establishment since the banking crises between 2017 and 2020 of which several of the local indigenous banks were taken over by the government of Ghana to help salvage depositors investments. "Insufficient" board level and senior management coordination as they were inactive and engaged in activities that inured to their interests rather than to the growth of the banks resulted in general poor corporate governance. Other causes were non-performing loans, board of directors who failed to oversee accounting and corporate reporting systems, managers who failed to provide proper functioning risk management frameworks and much more. It was clear that some managers of the Ghanaian local banks were unable to appreciate the usage of information technology-based AI thus resulted in poor decision making leading to the collapse of these Banks. Most pundits assert that the main reason behind the collapse of these banks was the poor deployment of IT systems. From all of the above the Research objectives are as follows:

1) To explore what way (s) leadership or executive managers in the Banking sector in Ghana use and implement effective systems and applications known as IT ("Information Systems”) based AI in their decision-making processes.

2) To evaluate the attitude of managers in the banking sector for the implementation and usage of applications based AI to improve satisfaction among customers for banking services and improve their productivity.

The objectives above were evaluated according to the following research questions: 
1) In which ways can Artificial Intelligence (AI) improve decision making of leadership of banks and also ensure customer satisfaction.

2) How can attitudes of leadership in the banking sector prevent implementation and adoption of AI related technologies.

3) What AI tools are available or can be developed and recommended to facilitate effective decision making at the banking sector.

\subsection{Model Conceptualizing Bank Leader's Ability to Adopt IT Systems Based AI}

Jarrahi (2018) opined that decision-makers confronted with ambiguity cannot adopt a rational and impartial decision-making approach but a subjective and intuitive one as it requires a common ground to rally the divergent parties at stake in the decision making (p. 5). Figure 1 below suggests a model conceptualizing bank leader's ability to adopt IT systems based AI.

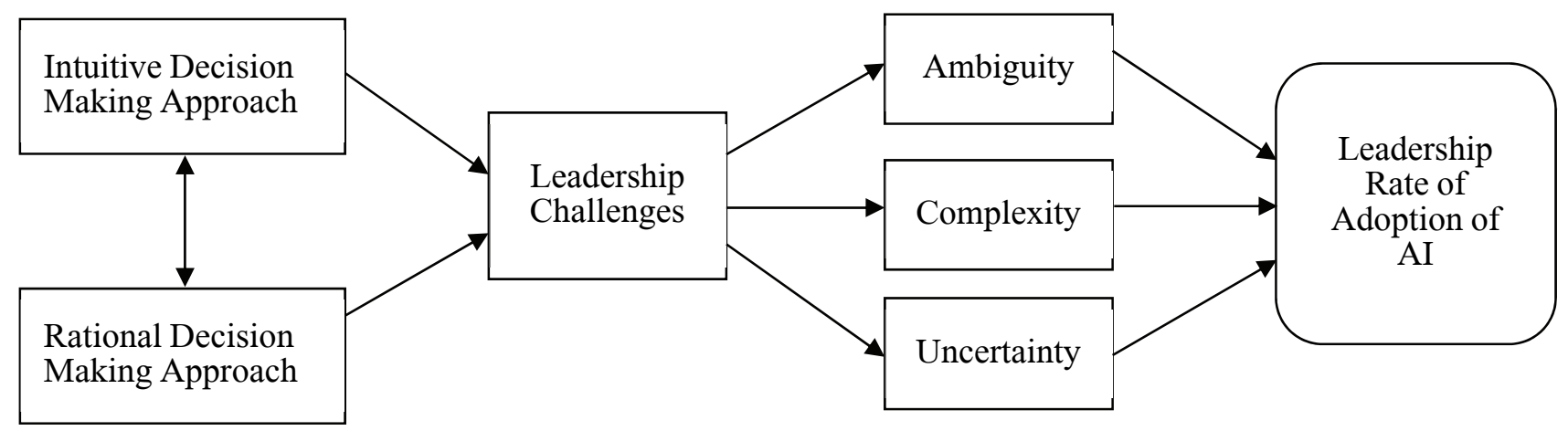

Figure 1: Model Conceptualizing Bank Leader's Ability to Adopt IT Systems Based AI

The figure 1 above suggests that there are two approaches by which leaders in banks take decisions; either through intuitive approach or rational approach. Intuitive decision is based on inherent or tacit knowledge of the leader, whiles rational decision is based on evidence related materials gathered through reports on activities of the bank. However, these approaches are not enough to deal with complex issues confronting leaders of banks. Although it is anticipated that IT based AI could mitigate this complexity, leaders of banks are often challenged by the ambiguity, complexity and uncertainty of IT based AI and hence affect bank leaders rate of adoption of IT based AI for decision making.

\section{Literature Review}

\subsection{Decision Support Systems in the Banking Sector}

Decision support systems (Hereinafter: "DSS”) is defined as information systems designed to support decisions-taking in the organization (Jessup and Valacich, 2003, p. 183; Hashem, 2016, p. 1060). Fanti et. al. (2017) describes a decision support system as an interactive computerbased system, which helps Managerial Directors to utilize data and models to solve the unstructured problem. It has been unveiled as an enabler for strategic decision-making in any productive organisation. A computerized program used to support determinations, judgments, and courses of action in an organization or a business and based on data science, managerial 
science, decision science, operational research, control theory and behavioural science through computer algorithms simulation and information technology is what most developed country viewed it (Fanti et al., 2017). The rapid business changes have led to a high degree of uncertainty in leadership and thus it was among the reasons for the need of business executives to have minute details of the suitable decision-making process at each stage of the company to help reflect the vision and the mission. Therefore, the use of DSS helps leadership to improve personal efficiency, speeding up the process of decision making, increasing organizational control, encouraging exploration and discovery as well as gives a competitive edge in the market. Braendle et. al. (2014) for example conducted a study to learn about their customer service using the gap model. The outcome studies showed that DSS helped to change output when inputs used for the DSS process are varied in the determination of the best use of communications technologies, data, documents, knowledge and/or models to complete decision process tasks. Interestedly in support of changes in output as a result of varied inputs, Manchanda and Mukherjee (2014) used Delone and Mclean model in evaluating DSS and concluded that proper implementation of DSS increases users' satisfaction and this influence customer's satisfaction from the bank's services in Oman.

The exploration of how much DSS is important in Ghana's banking sector had derived from previous events in the country. Ghana Banking sector experienced a crisis from 2016-2019 and according to Osman (2019), the Bank of Ghana in its post-mortem of the cause of the crisis attributed it to monetary policies and good corporate governance practices. Indeed, Osman (2019) further identified, that most of the failures were in leadership viz-a-viz huge sums of monies paid out by executives to themselves as emoluments, leadership negligence on the part of the past central government, general lack of fidelity to the fiduciary duties of boards of directors and Loan default and third party transactions. It is quite legitimate to assume that these problems are driven by poor data collection, storage, and management and leadership failures.

The development and implementation of DSS require knowledge and understanding of managerial decision making, levels of reasoning and problem solving and roles of managers in organizations (McNurlin and Sprague 1998). Unfortunately, the prerequisites for using computerized decision support already constitute a challenge for many leaders in the Banking sector in Ghana as the use of information technology is becoming much more complex especially for older people. Consequently, the mandate for a better future is incontestable nontrivial. The business sector in Ghana has found itself in recent times with the use of Strategies to help improve profitability, efficiency, stability and productivity (Alhassan, 2016; Duho et al., 2019). The complexity of banks operations in the absence of well define DSS process as most banks are relying upon technological initiatives in their operations such as mobile money banking, digital banking and ATMs. Sadly, while discussions regarding robotics process automation, artificial intelligence, blockchain, cloud computing, big data analytics and their application in the banking sector, these issues are considered as topical issues at the global level, so as there has not been any transformational implementation in the Ghanaian Industry. (Duho et al., 2019). Accordingly, the setback of high non-performing loans that have been devilled the banking sector is lingering on and in the absence of DSS processes led to nonadherence to credit management principles and procedures resulting in the high exposure of the Banks.

The foregoing discussions, "picture" the situation related to the level of appreciation of DSS in the banking sector in Ghana. It is clear that DSS has not been incorporated into businesses to support human intelligence for and therefore the level of appreciation is relatively low. More 
studies in the literature also point on the same situation and result as some authors like Rogers et. Al. (2013); Buckland, M., (2017); Wurman (2012); Dias (2014) listed difficulty in quantifying all the data, unaware of assumptions, system design failures may occur, difficulty in collecting all the required data and lack of technology knowledge in users. in effect information overload, too much dependence, devaluation of subjectivity, overemphasis on decision making and cost of development can cripple the entire leadership strategies.

\subsection{Leadership and Management in Banking}

There is a genuine need for leaders in every sphere of life. Leadership is considered an important discipline underpinning the development of an organization and the attainment of its corporate goals. In the absence of effective leadership, an organisation can't work efficiently as organisations are created to achieve certain objectives through a group of people and it is imperative to harness the contributions of a group of people and direct them to the attainment of such objectives (Owusu-Boadi, 2019). Effective leadership is therefore integral to the effectiveness of organizations at both the micro and macro level. Leadership is considered the key element that leaders all over the world should evaluate if they want to continue to live and function in a competitive economy. The most effective leaders produce and facilitate positive organizational cultures, strengthen motivation, clarify the mission and organizational objectives, and steer organizations to more productive and high performing outcomes (Paarlberg, and Lavigna, 2010). For example, Nayar (2013) identified the distinguishing factors between management and leadership to influence and inspired them. In his study, he described these factor as following: "Management consists of controlling a group or a set of entities to accomplish a goal.

Leadership refers to an individual's ability to influence, motivate, and enable others to contribute toward organizational success" (Nayar, 2013). Later studies such as the one of Furnham and Crump (2015) reiterated further that leadership in the modern technological world is not an aspect that depends on wealth, social class, or political influence but it is considered as a personal attitude and willingness to make better environment or a group from the situation or level in which they are to greater levels. Matiş et al. (2018) explored different clusters of leadership and management by using clustered analysis and management and suggested that leadership and management constitute the basis of the organizational culture of the banking system (Matis et al., 2018, p. 213). In their study the authors found the following factors: "concept, attribute, functions, post-crisis policies, opinions, organizational cultures, responsibilities within the organization and decision paths used to influence organizational cultures” (Matiş, et al., 2018, p. 216). The authors also used an ANOVA analysis to show that there are two were similar factors in the banking system. They concluded with a stronger conviction that good managers in banks ought to have leadership abilities to perform the established goals.

The central focus for leadership revolves around two variables namely task and people management (Mastrangelo et al., 2014 pp3-5). According to the authors, organizational performance is found as the main preoccupation of organizational leaders. This happened also in the Ghanaian Banking sector that has the inability of leadership to take decisions led to the financial crisis experienced in Ghana between the period of 2016-2019. These responsibilities have become more and more complex with the ever-growing technology and big data age. Artificial intelligence presents itself as a cutting edge solution to these complexities particularly in the area of management and leadership. To boost awareness and provide additional guidance for banks' corporate governance in developing countries like Ghana with AI-based system, Caron (2019), suggested various legal tools with differing effects, such as hard regulation, or 
such as voluntary codes of conduct which are available to private corporations and national governments alike with the aim of at promoting better transparency and legal certainty. This confirms mostly with ongoing regulatory developments in developed countries like Canada, the US and UK. It is even said EU in in general is delving into a broad-spectrum Data Protection Regulations specifically with decision-making and profiling applications of AI based systems. Michael E. Porter, a professor from Harvard University said “a nation's competitiveness depends on the capacity of its industry to innovate and upgrade" and the early developing countries like Ghana embrace and implement effectively AI based systems, the better it will enhance the productivity and strengthen national competitiveness. This is because there are ample literature and empirical evidence that, AI can augment human capacity by processing and analysing large datasets much faster than humans. AI holds immense potential for increasing productivity, most obviously by helping companies and people use resources more efficiently and by streamlining the way people interact with large sets of data. It is our believed that, $\mathrm{AI}$ is not a replacement, or substitute for human intelligence but a complement that work alongside with humans and offers new opportunities for creativity and innovation and therefore provides new ways of thinking by leaders.

\subsection{Integration of AI in the Banking Sector}

Globally an integration of AI in the financial sector has been perceived as a profitable enterprise. Financial institutions are gradually evolving from mainly using AI to reduce costs to utilizing their capabilities for revenue generation. AI has been employed to assist with cyber security aspects such as fraud detection, customer support and helpdesk through humanoids interfaces that can be used to increase efficiency and reduce costs for the benefit of customer interactions, risk management, wealth management and security improvement. AI has created a value in banking today through the acceleration of the decision-making process. In the recent years, financial institutions have been greatly impacted by the ingenuity and innovations facilitated by information technology (Preko and Kester, 2015). This is manifested in, for instance by the way in which banking operations having gradually developed from the mere exchange of physical cash, cheques to a more sophisticated application of Information Technology (IT) to transact business in the banking industry (Jakšič and Marinč, 2019). With the increasing pattern of data in the business sector particularly in the banking arena, it turned out that there is a great demand for finance applications and systems based AI.

The need to harness leadership skills with AI will bring relevant digitization services to banks and help them meet the competition posed by Fintech players. Studies conducted by National Business Research Institute and Narrative Science 2018 shows 32\% of financial service providers are already using AI technologies like Predictive Analytics, Voice Recognition, among others. It is strongly agreed that AI is the future of banking as it will bring the power of advanced data analytics to combat fraudulent transactions and improve compliance. Additionally, it will play a key role in managing huge volumes of data at record speed to derive valuable insights from it and AI bots, digital payment advisers and biometric fraud detection mechanisms lead to the higher quality of services to a wider customer base.

At the local scene, there has been a strenuous effort towards automation in Ghana due to the speedy improvement of Information and Communication Technology (ICT). Current studies have established two positive impacts regarding the relationship between ICT and banks' financial performance; First, ICT reduces banks' operational costs i.e. the cost advantage and second, it facilitates transactions among customers within the same network (Farrell and 
Saloner, 1985; Katz and Shapiro, 1985; Economides and Salop, 1992). Additionally, AI found its way into the financial sector in Ghana in 1995, through the installation of an automated teller machine (ATM) by The Trust Bank Ghana, Owusu-Frimpong (1994). This has led to the entrenchment of one-branch philosophy in Ghana. This innovation so to speak, opened the flood gates for other banks in the country to install their ATMs. For example, Agyapong (2020) identified that the banking sector is going to enter the 2000s area, thus it is crucial to turn its products, services and processes to digital. The first decade of the 21 century was characterized at the beginning of the journey with a cashless society and with the inception of the e-ZWICH biometric electronic payment system and by the end of the second decade, there was a surge in mobile and online banking and other forms of remote banking. Ingenuity particularly related to internet banking, there is a use of an automated virtual teller that is designed to form a personalization with client's financial experiences to provide services and support without human intervention. Swankie and Broby (2019) investigated the link between AI and banking risk management. They found that AI could be used to identify, measure and monitor the process affiliated with financial risks such as credit risk, liquidity risk, reputational risk and operational risk (Swankie and Broby, 2019, p. 8). However, challenges may exist in data security and also when the data provided is insufficient for analysis and receive accurate predictions that could lead to calculation errors. In the end, Swankie and Broby (2019, p.1416) posit that AI could make significant strides in the working environment and contribute to business value.

Another study conducted by Agarwal et al., (2019, p.14) looked into the application of AI for successful strategy implementation in India's banking sector. In this study, the authors claimed that the use of technologies in various banking processes could improve customer experience. Study's conclusion showed that this claim had become true. Although a lot would have to be done to achieve integration with AI to fully enjoy its benefits in banking, there is still a long way to implement that. In another study, Truby et al. (2020) shed light on the need for AI regulation in the financial sector to prevent "unprecedented risks" (Truby et al., 2020, p. 110).

The transformation in the development of AI-based systems deepen changes in social communication in the banking sectors and there has been a shift from the traditional system which is consuming time and not providing customer satisfaction in the banking services. Hence in the growing AI-based systems the requires leaders to fully understand to help clients improve the process and fulfil the demand of Customer. Thus AI will not only empower banks by automating their knowledge workforce, but it will also make the whole process of automation intelligent enough to do away with cyber risks and will enable banks to leverage human and machine capabilities optimally to drive operational and cost efficiencies, and deliver personalized services.

\section{Methodology}

The study employed qualitative research techniques to gather data for analysis. This technique was chosen because of the nature of the study which intends to derive "more depth" data from the encounters of participating respondents.

Data were collected from both primary and secondary sources where 15 subjects from the banks in Ghana, were asked open questions. The answers were recorded in an excelTM sheet. This mix of methods and sources resulted in a well-rounded, yet current, insight into the subject area. Primary data was collected using open ended questions, as they tend to maximize the 
efficiency and flexibility of the questionnaire (Corbetta, 2003). Although structured questions are easier to analyze, they may miss important information due to their narrow focus (Corbetta, 2003). The open ended questionnaire was administered to 15 banking institutions from a population of 23 banks and 25 special deposit-taking institutions in Ghana using the purposeful sampling technique due to the nature of the research and respective objectives. Data were collected on topics such as types of IT system based AI in the banking sector, attitude towards the implementation of technology based AI in Ghana, the process of choosing and implementing technology based AI in the banking sector and how technology based AI may strengthen leadership on daily decision making in the bank.

Secondary data sources were obtained from relevant literature. This enabled me to establish whether the findings obtained are within the boundaries of existing findings. Furthermore, a study was carried out by investigating others' interpretations and then filtering them to construct knowledge that was used to design a conceptual model to establish the bank leader's ability to adopt IT Systems based AI.

Data analysis was conducted by using orangeTM 3.28 version, in which the Corpus viewer was used. The analysis related to bag-of-words, and distance between 2,3 pairs were used by the distance object. The word of cloud which is a common method (Lohmann et al., 2015) and the hierarchical clustering (Murtagh and Contreras, 2012) were used to analyse the context of each respondent within each questions. Since data related to questions: 3 \& 10 were answered by most of the respondents, further analysis related to this questions was used. The questions were as follows:

Questions 3: "Can you tell me; how do you consider the adoption for IT Systems based AI in the Banking Sector in Ghana?"

Questions10: "Do you think that technology based AI may strengthen the leadership on daily decision making in the bank? If yes please elaborate how, if not please elaborate why do you think that it will not improve the DSS process or leadership management?"

\section{4. $\quad$ Results}

The analysis of the positions of the 15 respondents interviewed in the banks were as follows; Chief's position constitutes 20\% and included Chief Digital Officer and Deputy CEO/Chief Financial Officer and General Manager, IT. 60\% were heads of department (Head, MIS \& Technology; Head, Digital Financial Services; Head of Technology; Head, Operational and Credit Risk; Divisional Head, Retail Banking; Head, Compliance; Head, Cyber \& Information Security; Head of IT) who formed majority of respondents interviewed and the remaining $20 \%$ were managers whose ranking in the hierarchical structure of the bank is below the heads of department and they included MIS Manager, Senior Manager, ICT and Operations Officer.

The numbers of years' respondents have worked in the various banks averages 13.4 years of the total sample size and managers that have worked for more than 20 years constitutes $20 \%$ of the sample. The study reveals that most of these managers with over 20 years of experience are those at the top management position. Those who have worked between 13-18 years were made up of $47 \%$ with the least being seven (7) months old in their current position. All the respondents (100\%) agreed that IT systems based AI can change the way decision making is done by leadership in the banking sector of Ghana. 
It is worthy to note that $60 \%$ of the respondents have had experience in the implementation of technology based AI solutions in the banking sector of Ghana and the solutions implemented included; credit scoring, anti-money laundering, business intelligence, customer relationship management and financial administration systems.

Analysis of the text context by bag of words, shows that related consideration and adoption of IT Systems based AI in the Banking Sector of Ghana, exhibits that managers believe it can assist the banking sector by means of reducing risks, detect fraud and serve as practical solutions for the improvement of the customer's service (Figure 1). Hierarchical clustering related to the adoption of AI in the banking sector of Ghana, reveals that among many objectives one of the main prominent is to increase customer's satisfaction (refer to cluster 11, Figure 2).

Analysis of the text context by bag of words, shows that related to effect of AI based technology to the leadership strategy taken by managers, in the Banking Sector of Ghana, Figure 3 exhibits that bank managers believe that it will cause positive emotions, reduce risks and improve the execution of new bank operations. Hierarchical clustering related to the contribution of AI based technology on leadership reveals that such technologies may assist in strengthening decision making, and reduce time to reach critical decisions (Figure 4)

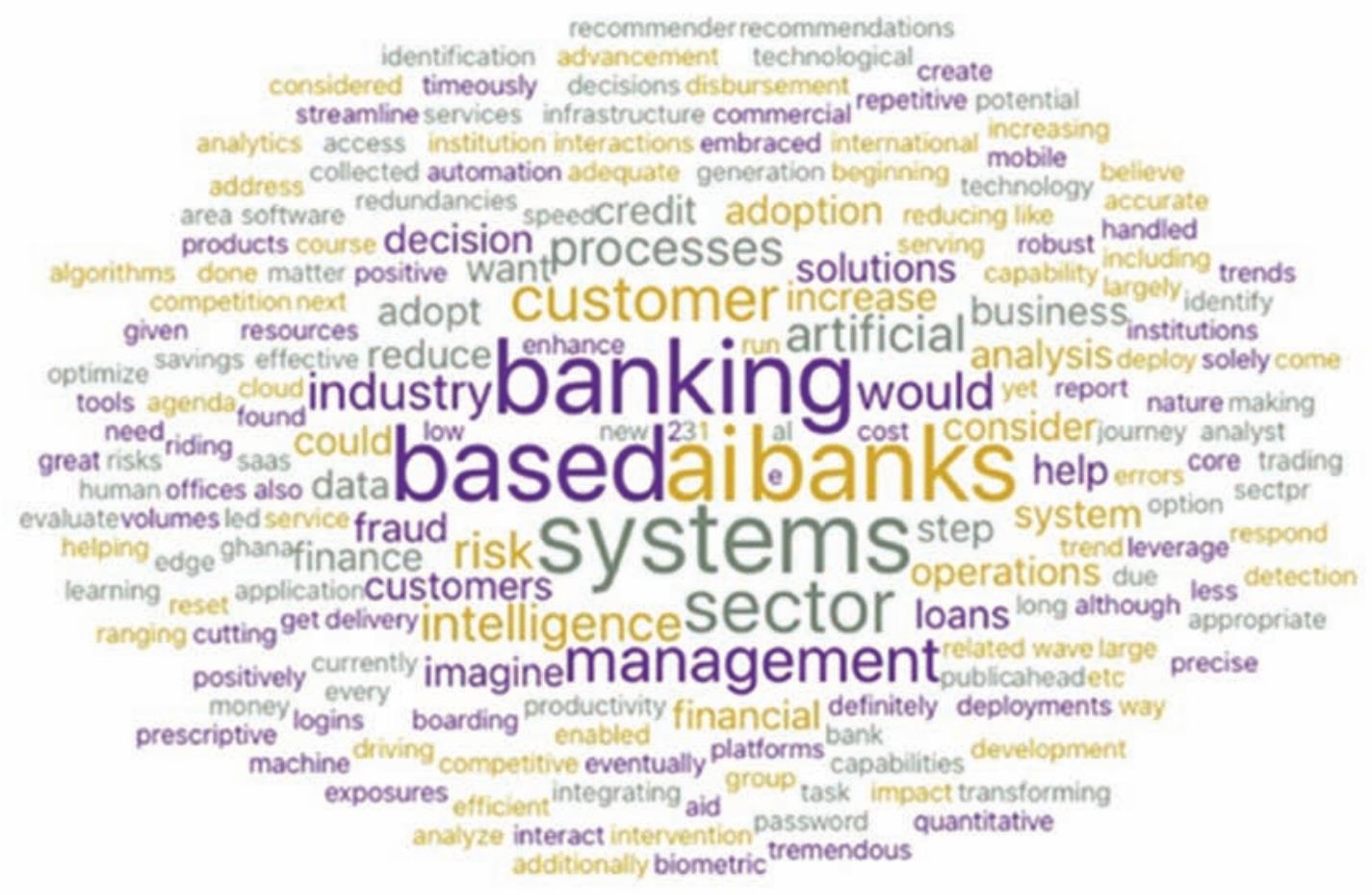

Figure 1: Cloud Tag related to the adoption of new technologies in the banking sector 


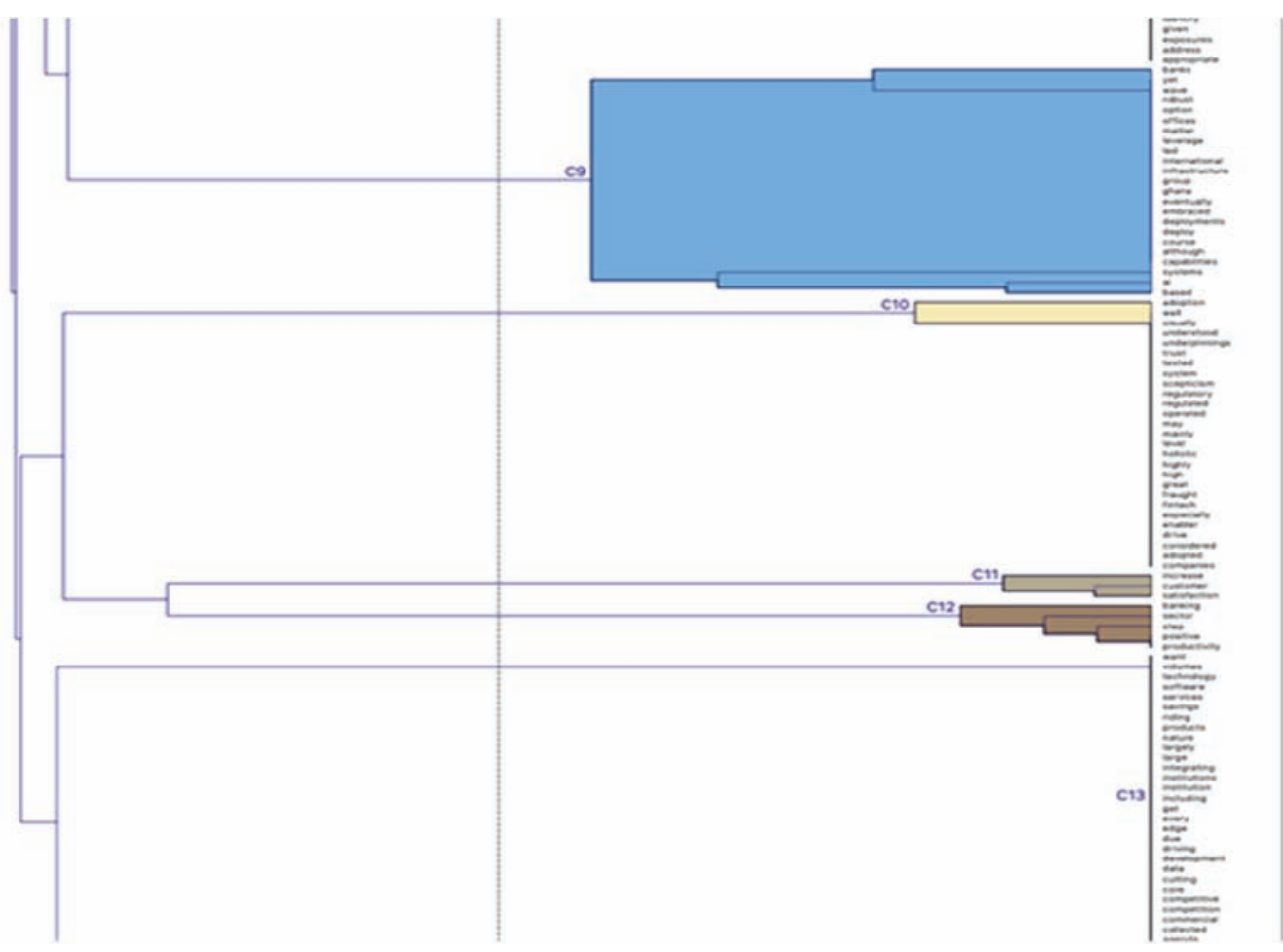

Figure 2: Hierarchical Clustering related to the adoption of new technologies in the banking sector.

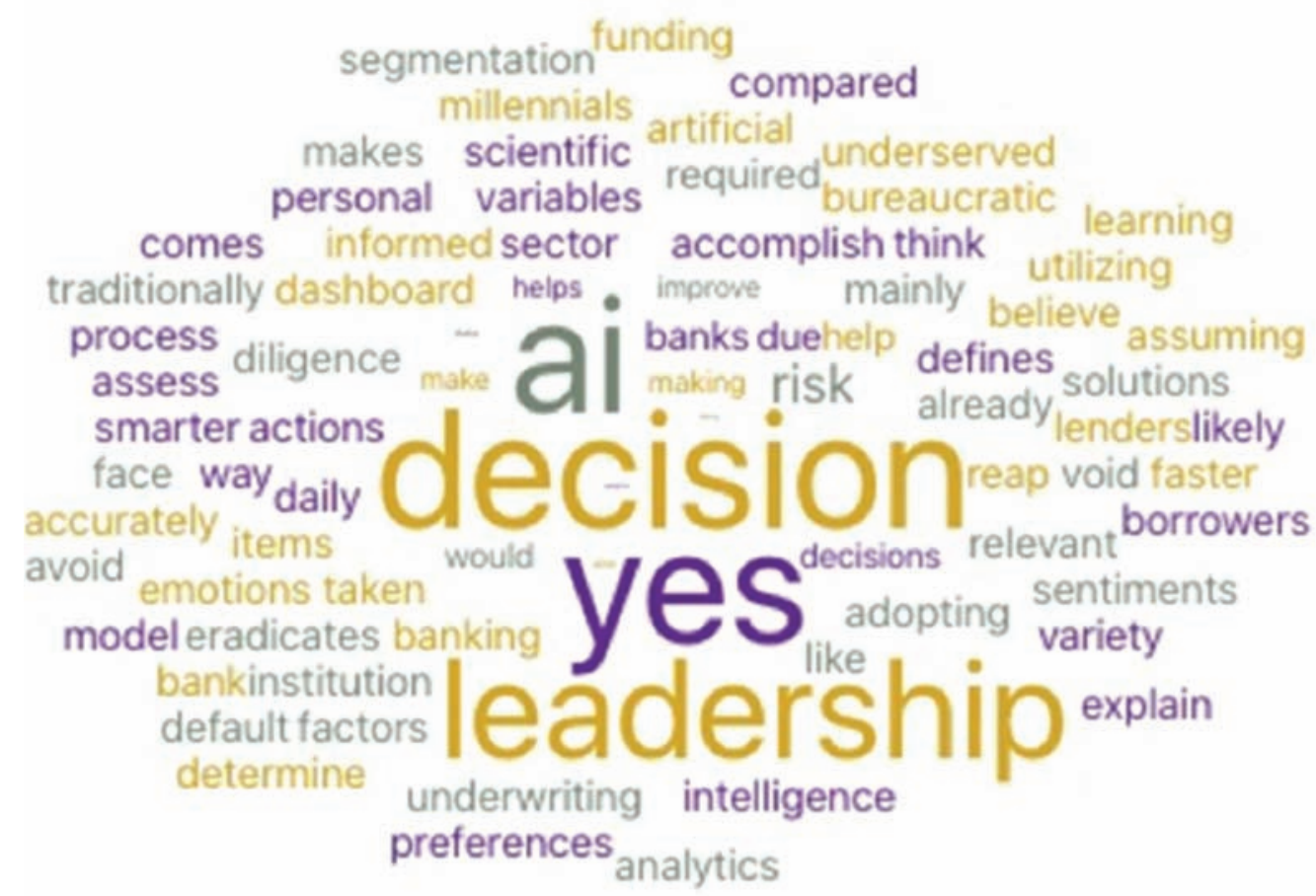

Figure 3: Cloud Tag related to the contribution of AI based technology to the leadership of managers in the banking sector in Ghana. 


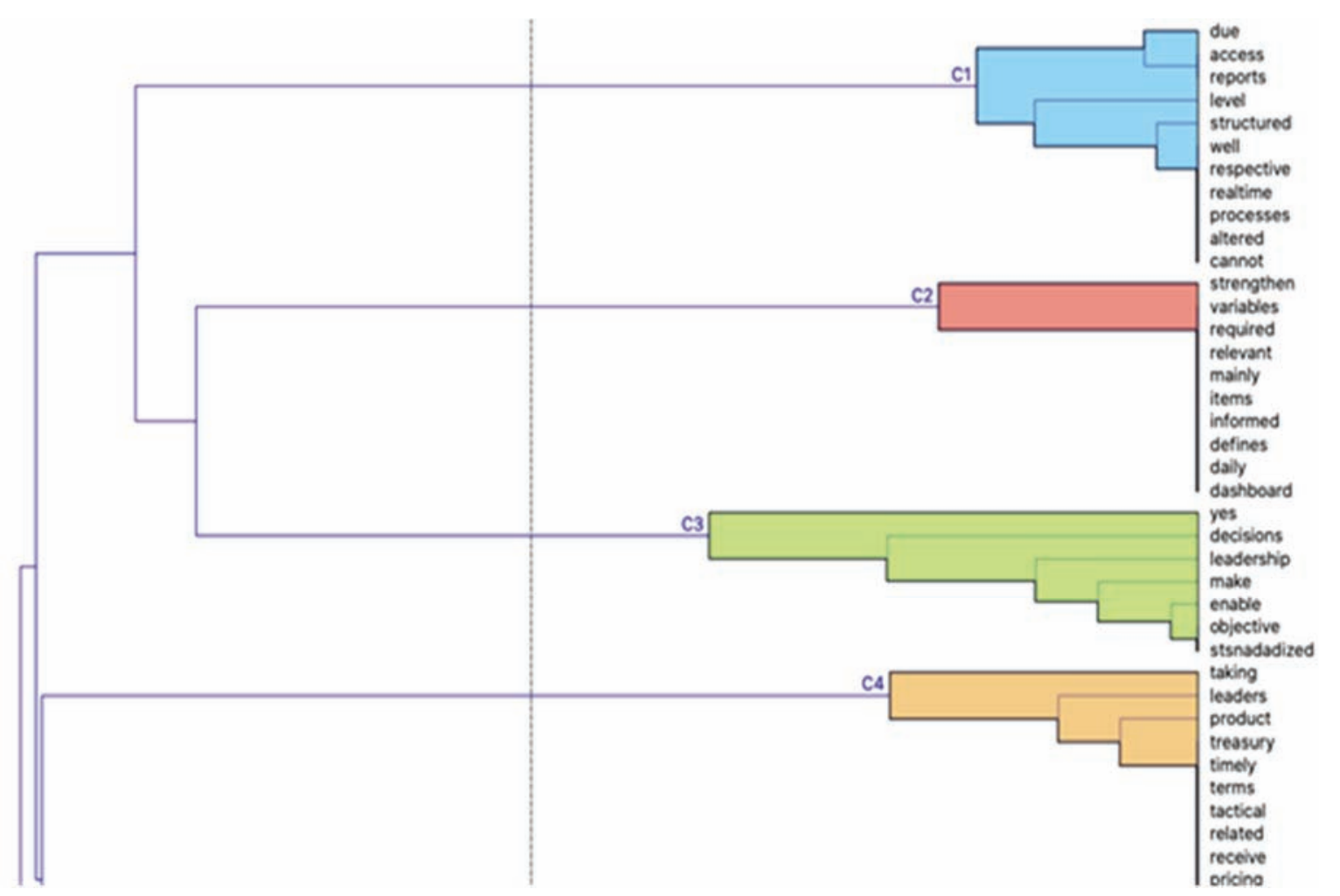

Figure 4: Hierarchical Clustering related to the contribution of AI based technology to the bank leadership objectives.

\section{Discussion}

According to preliminary results taken from 15 respondents, we may say that AI-based technology is needed for service improvement and decision making in the banking sector in Ghana. The literature also supports our findings, since it was shown by (Duan et al., 2019 pp 63-71), that the adoption of AI-based technology improves decision making. Payment fraud, risk management, loan approvals, credit scoring, deposit collections, customer acquisition and retention, cross-sell and up-sell are a few areas leadership of banks can take advantage of in the implementation of AI-based technology.

The role of the top to middle management positions in Ghanaian Banks are mostly filled by promotions held within the bank but often MBA candidates with 5-10 years of job experience are also recruited for various position. Section 60 of Act 930 of Bank of Ghana (BoG) regulation prescribes, among others, the need for banks for prior written approval before the appointment of a Chief Executive Officer or a Deputy is done. Banks must have a board to provide oversight responsibility to the top management with separation of powers as part of the leadership. The study reveals that, the common leadership positions across the banks were MD/CEO, Deputy MDs, Chief Financial Officer in some cases Chief Operating Officer as top management and these are closely followed by various heads of department. Dance (2019 pp. 8-14.) indicated that these heads of department constitute middle level management and are mainly responsible for 'team leading' line managers and also indirectly in charge of the junior staff that drive performance and productivity. It is therefore not surprising that they formed the majority (60\%) of the respondents as they seem to hold the key to understanding the operational leadership strategies and Decision Support Systems based AI in the various banks. 
Overwhelmingly, all respondents agreed that IT systems based AI can change the way decision making is done in the banking sector of Ghana. This was shown during the covid-19 pandemic immediate response where some of the banks adopted cost containment measures through temporary closing of branches and communicated to customers through social media as against the traditional newspaper and billboards and also provided services through digital services. Respondents are of the view that, banks in Ghana must enhance digitization in their operations to cushion against the forecasted decrease in operational results. Therefore, it is clear that IT systems based AI can change the way decisions are made through digitization in combination with advances in data analytics (McKinsey G.I 2018). The use of AI has led to increases in revenue and profit as well as a decrease in costs through better customer targeting, the optimization of business operations, and the identification of better locations for the branch networks, among other things (Königstorfer \& Thalmann, 2020 p9).

Even though AI in banking is currently mainly applied, Casu et al. (2016) are of the view that limited attention of research on how commercial banks can apply AI in several core business areas has created a business and leadership gap which non-banking firms with Fintech applications are competing fiercely to reduce the banks' revenue up to $40 \%$ and that banks must react appropriately through technology based AI to compete favourably (McKinsey 2016). Subsequently the innovations in digital banking platforms such as deposit-accepting, automated teller machines, mobile banking including the use of USSD codes, internet banking and corporate electronic banking have also change the leadership perception during the covid19 pandemic where some bank executive managers are of the view that they needed to revise strategies for pursuing growth in deposits in the future. Some respondents confirmed that even though expanding the capacity of their IT function had always been a key strategic agenda, recent trends of customer demand for remote/digital banking in the past few months had brought the expansion need to the fore and quickened the process to achieve this. The bank therefore in recent months has shortened the timelines of key milestones for digital transformation, revised projected financial performance downwards and realigned human capital strategy and operations to the changing AI trends in banking.

High credit risk in the Banking industry was the top concern of leadership. Bank leadership anticipate heightened credit risk factors will linger a while and will impact on future credit profiling of customers and the subsequent measurement of Expected Credit Losses (ECL) in the coming years. Therefore, some of them have implemented short term measure of product innovations such as mobile loan application and repayment as an opportunity to widen the scope of banking activities. Some banks experienced an increase in the uptake of existing digital products whose patronage before Covid-19 was low. This has necessitated changes in the implementation of technology-based AI solutions in the medium and long term additional investment that may require the provision of robust substitute for the reduced banking hours. The need for secure virtual private networks (VPNs) and the smooth interfacing of banking applications with other tools for remote working to ensure data security also topped the discussions. Banks leadership are also critical of their workforce's knowledge on cybersecurity and tools for remote working as the banks' increased reliance on technology-based AI solutions for internal operations.

\section{Conclusions}

To conclude we believe that the preliminary study had shown a positive effect on the willingness to adopt new technologies based AI and their contribution to decision making. The 
finding of this paper reveals managers from the banking sector in Ghana and this must apply to developing economies are keen to adopt technology-based AI but the eagerness has been exacerbated as a result of the Covid-19 pandemics.

However, additional analysis is needed to be taken on more answers provided by respondents. Improvement of the findings is needed by the collection of more data from a substantial data sample ( $\mathrm{N}$ should $=150$ ). The study also revealed that the covid-19 pandemic has presented opportunity for banks in Ghana to implement technology based AI solutions as a way to expand their products and services to their customers and also improve their bottom line objectives. Regardless of the level of planned investments in technology-based AI solutions, the banks had to make decisions to quickly implement these technologies to support remote working and social distancing of both staff and customers. We understand that most banks sought to balance this requirement of incurring an additional cost with some actions like the temporary closure of some branches, a freeze on staff recruitment and usage of non-essential goods and services to cover the additional budgets.

The majority of banks have also revised their mode of engagement with customers as they now look to deliver exceptional service through technology-based AI solutions. While technology has proven to be the bedrock of the 'new normal' banking in Ghana, bank leadership express divergent views on whether developing and engaging IT specialist, IT infrastructure or partnerships with Fintech also required long term investment.

\section{References}

Alhassan, A.L. \& Asare, N. (2016), “Intellectual capital and bank productivity in emerging markets: evidence from Ghana”, Management Decision, Vol. 54 No. 3, pp. 589-609.

Agarwal, B., Agarwal, H., \& Talib, P. (2019). Application of Artificial Intelligence for Successful Strategy Implementation in India’s Banking Sector. International Journal of Advanced Research, 7(11), 157-166. https://doi.org/10.21474/ijar01/9988

Agyapong, D. (2020). Implications of digital economy for financial institutions in Ghana: an exploratory inquiry. Transnational Corporations Review, 1-11

Allen, J. (1998). AI Growing Up The Changes and Opportunities. AI Magazine, 19(4).

Autor, D. H. (2015). Why Are There Still So Many Jobs? The History and Future of Workplace Automation, The Journal of Economic Perspectives, 29(3), pp. 3-30. doi: 10.1257/jep.29.3.3

Brachman, R. (2006). (AA) AI More than the Sum of Its Parts. AI Magazine, 27(4), 1-16.

Braendle, U., Sepasi, S., \& Hossein Rahdari, A. (2014). Fuzzy Evaluation of Service Quality in The Banking Sector: A Decision Support System. Fuzzy Economic Review, 19(02). https://doi.org/10.25102/fer.2014.02.04

Buckland, M. (2017). Information and Society. Massachusetts: MIT Press. pp. 1-2. ISBN 978-0-262-53338-6.

Casu, B., \& Girardone, C. (2016). The efficiency of large banks in the single European market. Service Industries Journal. 24.

Caron, M. S. (2019). The Transformative Effect of AI on the Banking Industry. Banking \& Finance Law Review, 34(2), 169-215.

Corbetta, P. (2003) Social Research: Theory Methods and Techniques. SAGE Publications Ltd., London.

Dalvinder, S. G. (2014). A Critical Conceptual Analysis of Definitions of Artificial Intelligence as Applicable to Computer Engineering OSR, Journal of Computer Engineering (IOSR-JCE) e-ISSN: 2278-0661, pISSN: 2278-8727 Volume 16

Dance, A. (2019). Pragmatic Introduction to Middle Management. Amazon: eBook. Pp. 8-14. ASIN B07L4D3QB9.

Davenport, T. H. (2018). From analytics to artificial intelligence. Journal of Business Analytics, 1(2), 73-80.

Debrah, Kwesi (2018). Collapse of indigenous banks due to corporate governance failure - Banking consultant. myjoyonline. Retrieved 14 February 2019.

Dias, P. (2014). "From 'infoxication' to 'infosaturation': a theoretical overview of the cognitive and social effects of digital immersion". Ambitos. 24. ISSN 1988-5733. 
Donepudi, P. K. (2017). Machine Learning and Artificial Intelligence in Banking. Engineering International, 5(2), 83-86.

Duan, Y., Edwards, J. S., \& Dwivedi, Y. K. (2019). Artificial intelligence for decision making in the era of Big Data: evolution, challenges and research agenda. International Journal of Information Management, 48, 63-71. https://doi.org/10.1016/j.ijinfomgt.2019.01.021

Duho, K.C.T., Onumah, J.M. \& Owodo, R.A. (2019), "Does diversification, competition and ownership impact the profitability, profit efficiency and financial stability of banks in frontier markets?”, 5th School of Social Sciences International Conference, University of Ghana Printing Press, Accra, p. 38

Evaluation of Banking Risk. Retrieved 17 March 2021, from https://www.researchgate.net/publication/337908452_Examining the_Impact_of_Artificial_Intelligence on the_Evaluation_of_Banking_Risk.

Frey, C. B. \& Osborne, M. A. (2013). The future of employment: How susceptible are jobs to computerization? Oxford: Oxford Martin School. Available at: https://www.oxfordmartin.ox.ac.uk/downloads/academic/

Furnham, Adrian, \& John Crump. 2015. "Personality and Management Level: Traits That Differentiate Leadership Levels". Psychology 06 (05): 549-559.

Gonçalves, T., Ferreira, F., Jalali, M., \& Meidutė-Kavaliauskienė, I. (2015). An Idiosyncratic Decision Support System for Credit Risk Analysis of Small and Medium-Sized Enterprises. Technological and Economic Development of Economy, 22(4), 598-616. https://doi.org/10.3846/20294913.2015.1074125

Farrell, J., \& Saloner, G. (1985). Standardization, Compatibility and Innovation. RAND Journal of Economics, 16, 70-83. https://doi.org/10.2307/2555589

Hashem, T. (2016). Commercial Banks Use of Decision Support System to Achieve Marketing Creativity International Review of Management and Business Research, 5(3), 1059-1067. https://edition.cnn.com/2019/04/14/africa/google-ai-center-accra-intl/index.html

Jarrahi, M. H. (2018) 'Artificial intelligence and the future of work: Human-AI symbiosis in organizational decision making’, Business Horizons. Elsevier Ltd, 61(4), pp. 577-586. doi:10.1016/j.bushor.2018.03.007

Jivan, A. (2020). A case study of the evolving management of leadership development in the retail banking sector. SA Journal Of Human Resource Management, 18. https://doi.org/10.4102/sajhrm.v18i0.1155

Katz, M., \& Shapiro, C. (1985). Network Externalities, Competition, and Compatibility. The American Economic Review, 75, 424-440

Kirsh, D. (1991). Foundations of AI: The big issues. Artificial Intelligence, 47(1-3), 3-30. doi: 10.1016/00043702(91)90048-0

Königstorfer, F., \& Thalmann, S. (2020). Applications of Artificial Intelligence in commercial banks - A research agenda for behavioural finance. Journal of Behavioral and Experimental Finance, 100352.

Lewis, W. P. C., \& Monett, D. (2018). Text Analysis of Unstructured Data on Definitionsof Intelligence. In Proceedings of The 2018 Meeting of the International Association for Computing and Philosophy, IACAP , pp. 1-12.

Lohmann, S., Heimerl, F., Bopp, F., Burch, M., \& Ertl, T. (2015, July). Concentri cloud: Word cloud visualization for multiple text documents. In 2015 19th International Conference on Information Visualisation (pp. 114-120). IEEE.

Makridakis, S. (2017). The forthcoming Artificial Intelligence (AI) revolution: Its impact on society and firms. Futures, 90, 46-60. doi: 10.1016/j.futures.2017.03.006

Manchanda, A., \& Mukherjee, D. (2014). Validation of DeLone and McLean model to analyze decision support systems success in the banking sector of Oman. International Journal of Computers \& Technology, 13(12), 5210-5221. https://doi.org/10.24297/ijct.v13i12.5280

Matiş, C., Ismana, M., Ghinea, A., \& Lang, G. (2018). Measuring the Convergence between Management and Leadership in the Banking System by Applying a Cluster Analysis. Review Of International Comparative Management, 19(2), 213-228. https://doi.org/10.24818/RMCI.2018.2.213

Mastrangelo, A., Eddy, E. R., \& Lorenzet, S. J. ( 2014). The relationship between enduring leadership and organizational performance. Leadership \& Organizational Development Journal, 35, 590-604. doi:10.1108/LODJ-08-2012- 0097

McCarthy, J. (1995). What has AI in Common with Philosophy? http://www.formal.stanford.edu/jmc/

McNurlin, B. C. \& R. Sprague Jr. (1998). Information Systems Management in Practice, Fourth Edition, Prentice Hall, New Jersey

Murtagh, F., \& Contreras, P. (2012). Algorithms for hierarchical clustering: an overview. WIREs Data Mining Knowl Discov 2012, 2: 86-97 https://doi.org/10.1002/widm.53R

Nilsson, N. (2009). The Quest for Artificial Intelligence: A History of Ideas and Achievements. http://www.cambridge.org/us/0521122937

Owusu-Boadi, B.Y. (2019). "The Role of Strategic Leadership in the Profitability of Large Organizations". Walden Dissertations and Doctoral Studies. 7890. https://scholarworks.waldenu.edu/dissertations/789 
Owusu-Frimpong, D. (1995). Customer adoption of e-service: an experimental study. International Journal of Service Industry Management, 12 (2), 184-207.

Preko, M., \& Kester, Q. A. (2015). The study of the impact of business intelligence in the banking industry of Ghana. International Journal of Emerging Research in Management \& Technology, 4(8), 31-36.

Randall P., W., (1996) The future of leadership riding the corporate rapids into the $21^{\text {st }}$ century ISBN 13 9780273622062.

Rogers, P., Puryear, R., \& Root, J. (2013). "Infobesity: The Enemy of Good Decisions".

Russell, S., \& Norvig, P. (2016). Artificial intelligence (3rd ed.). Essex: Pearson Education Limited.

Swankie, G., \& Broby, D. (2019). Examining the Impact of Artificial Intelligence on the Evaluation of Banking Risk. https://www.researchgate.net/publication/337908452

Truby, J., Brown, R., \& Dahdal, A. (2020). Banking on AI: mandating a proactive approach to AI regulation in the financial sector. Law and Financial Markets Review, 14(2), 110-120. https://doi.org/10.1080/17521440.2020.1760454

Three Differences Between Managers and Leaders. Harvard Business Review. (2021). Retrieved 17 March 2021, from https://hbr.org/2013/08/tests-of-a-leadership transiti\#: :text=Management\%20consists\%20of\%20controlling\%20a,managers\%2C\%20not\%20power\% 20and\%20control.

Van L. R. (2018). "Making Innovation More Competitive: The Case of Fintech". UCLA Law Review. 65 (1): 232 Western, S. (2019). Leadership: A critical text. London: Sage. ISBN 978-1-5264-5951-0

Wurman, Richard Saul (2012). "Information Anxiety: Towards Understanding". Scenario Journal. https://narrativescience.com/Offers/The-Rise-of-AI-in-Financial-Services 